\title{
UPACARA ADAT TENGGER DI AMBANG KOMODIFIKASI: MERAWAT TRADISI DARI ANCAMAN DESAKRALISASI
}

\author{
Rahmi Febriani ( $\left.{ }^{*}\right)$, Edi Dwi Riyanto (2) \\ ${ }^{12}$ Faculty of Humanities, Universitas Airlangga, Surabaya, Indonesia
}

\section{ARTICLE INFORMATION}

$\begin{array}{ll}\text { Submitted } & : 08^{\text {th }} \text { January } 2021 \\ \text { Review } & : 08^{\text {th }} \text { Nopember } 2021 \\ \text { Accepted } & : 17^{\text {th }} \text { Nopember } 2021 \\ \text { Published } & : 18^{\text {th }} \text { December } 2021 \\ \text { Available Online }: \text { December } 2021 .\end{array}$

\section{KEYWORDS}

Traditional ceremony; commodification; adaptation; desacralization; Tengger

CorRespondence

*E-mail: rahmifebriani2@gmail.com

\begin{abstract}
A B S T R A C T
The phenomenon of profanation of sacred traditions in the tourism industry is increasingly prevalent. Considering that matter, some steps should be taken to avoid the tradition of desacralization. This research was done by a field research approach to identifying the values of the traditional ceremony of Tengger, especially Yadnya Kasada, Yadnya Karo, and Unan-unan. This research was located in Tosari and Ngadiwana Village, Tosari, Pasuruan, East Java. The data was collected by unstructured and open-ended interviews. The results showed that their beliefs and obedience in conducting the ancestral teachings must be balanced through a deep and comprehensive understanding of traditional values. On the other hand, adaptation strategies must be carried out to stabilize themselves with modernization. These are done to preserve the existence of tradition without eliminating the essence of sacredness that has been attached to it. Therefore, one of the steps that can be taken is to separate the tradition from commodification without resisting the flow of modernization.
\end{abstract}

\section{A. PENDAHULUAN}

T ak dimungkiri, eksotisme alam dan budaya Tengger adalah perpaduan yang sangat luar biasa. Dalam istilah Sutarto (2006), Tengger disebut sebagai Pusaka Saujana (cultural landscape) yang apabila dibina dan dikelola dengan benar, eksistensinya akan memberikan sumbangsih yang lebih berarti bukan hanya bagi dirinya, melainkan juga bagi Indonesia. Namun demikian, mengelola alam, budaya, dan masyarakat adat adalah satu hal yang sangat kompleks. Faktanya, masih banyak persoalan-persoalan dilematis yang melingkupi Tengger, terutama dalam hal pariwisata. Sebagaimana pendapat Mba (2020, p. 198), tidak semua wilayah berhasil mengembangkan sektor pariwisata secara optimal. Alih-alih menghilangkan kemiskinan, kehadiran pariwisata juga memungkinkan menimbulkan permasalah-an sosial lainnya. Demikian pula di Tengger. Dalam opini Pramono yang ditulis di media Kumparan.com (2020), ia mempersoalkan siapa sebenarnya pengelola kawasan wisata Taman Nasional Bromo-
Tengger-Semeru (TNBTS)? la melihat masih terdapat banyak ketimpangan dalam pengelolaan kawasan wisata ini. Secara khusus, pengelolaan kawasan pariwisata Gunung Bromo dilakukan oleh Balai Besar TNBTS sebagai unit pelaksana teknis yang diberikan kewenangan untuk mengelola TNBTS oleh Direktur Jenderal KSDAE Kementerian Lingkungan Hidup dan Kehutanan (Utami, 2017, p. 25). Namun, secara umum, pengelolaan kawasan TNBTS dipegang oleh pemerintah provinsi. Perlu diingat pula bahwa kawasan TNBTS berada di empat wilayah administratif, yaitu Probolinggo, Lumajang, Pasuruan, dan Malang. Dalam konteks ini, lebih lanjut Pramono mengungkapkan bahwa persoalan-persoalan koordinasi antarlembaga masih belum dilakukan secara maksimal. Terlebih, manajemen anggaran, manajemen pengunjung, manajemen kendaraan/lalu lintas, dan persoalan ketersediaan air bersih semestinya diprioritaskan untuk diselesaikan terlebih dahulu. 
Di samping itu, kemajuan pariwisata TNBTS yang cukup progresif sedikit-banyak telah memberikan pengaruh terhadap masyarakat dalam memandang tradisi, terutama upacara adat sebagai warisan nenek moyang Tengger. Tradisi menjadi unsur terpenting bagi kebudayaan guna menciptakan nilai etik dan estetika, ... sehingga terbentuk keseimbangan antara nilai material dan nilai spiritual di dalam kehidupan masyarakat (Syafrita \& Murdiono, 2020). Upacara adat Tengger yang termasuk ke dalam perayaan besar, di antaranya Hari Raya Yadnya Kasada, Hari Raya Yadnya Karo, dan upacara Unan-unan. Secara khusus, tulisan ini akan berfokus pada tiga upacara adat besar tersebut dengan alasan: (i) Hari Raya Yadnya Kasada, Hari Raya Yadnya Karo, dan upacara Unan-unan adalah upacara adat yang melibatkan massa dalam jumlah besar, dan (ii) ketiganya adalah upacara adat yang 'memikat' wisatawan untuk bertandang ke Tengger sambil turut menyaksikan gelaran upacara, terutama upacara Kasada yang dilaksanakan di kawasan Gunung Bromo.

Kemajuan pariwisata TNBTS senyatanya adalah kemajuan bagi pihak-pihak yang berkecimpung dalam sektor pariwisata. Potensi pariwisata yang melesat di TNBTS menjadi ladang subur yang 'menggiurkan' untuk meraup keuntungan lebih secara ekonomis. Terlebih, ketika kegiatan pariwisata diintegrasikan dengan aktivitas kultural seperti upacara adat dapat meningkatkan jumlah kunjungan wisatawan. Sebagaimana dalam upacara Kasada, kegiatan wisatawan Gunung Bromo saat kegiatan upacara Kasada meningkatkan jumlah pengunjung sebanyak $50 \%$ (Hikmah et al., 2020, p. 113). Tidak menutup kemungkinan, jika kebutuhan masyarakat Tengger secara ekonomis tidak terpenuhi, lambat-laun tradisi Tengger akan dikendalikan oleh hasrat profan, dikomodifikasi dari berbagai sisi, dan disajikan dalam kemasan pariwisata.

Menilik jauh ke belakang, fenomena semacam ini telah lebih dulu terjadi pada masyarakat Bali. Sebagai contoh, tari Kecak yang pada mulanya merupakan tarian sakral masyarakat Bali. Namun, sejak tahun 1930-an, tarian ini mengalami desakralisasi dengan berubah menjadi kesenian tradisional tersendiri yang menyajikan performansi dengan latar belakang cerita Ramayana (Sasongko, 2019). Meski dalam pementasannya tari Kecak tetap melibatkan unsur-unsur magis, tetapi komodifikasi yang dilakukan telah menghilangkan nilai-nilai kesakralan di dalamnya. Durkehim (2011, p. 338) mengungkapkan bahwa kesakralan akan berubah jika terjadi perubahan padanya. Lebih lanjut, (Dewi, 2016, p. 230) menegaskan bahwa bersamaan dengan terjadi nya komodifikasi terjadi pula proses profanisasi atau desakralisasi. Dalam hal ini, penyelenggara, turis asing, dan kebanyakan para penonton, melihat dan menikmati tarian tersebut dengan sikap yang nonreligius, profan, dan dianggap sebagai tontonan biasa (Sasongko, 2019).

Peristiwa di atas adalah kaca benggala bagi wilayah-wilayah lainnya yang memiliki karakteristik serupa, yakni wilayah pariwisata yang berlimpah kekayaan kultural dan ramai lalu lintas kepariwisataannya. Oleh karena itu, tak menutup kemungkinan jika peristiwa tersebut juga terjadi di wilayah kebudayaan lainnya, termasuk Tengger. Upacara Hari Raya Yadnya Kasada, Hari Raya Yadnya Karo, dan Unan-unan memiliki peran dan fungsi yang penting bagi masyarakat Tengger dalam melaksanakan ritus warisan leluhur (titi luri). Titi luri dihayati oleh masyarakat Tengger sebagai sikap taat dan patuh terhadap ajaran leluhur, seperti meneruskan agama, kepercayaan, dan adat istiadat yang dijadikannya sebagai otoritas dalam menjalankan kehidupan (Hasanah \& Sukmawan, 2020). Jika fungsi tersebut berubah dengan menjadikan upacara adat sebagai komoditas, dapat menjadi sebuah ancaman bagi kekokohan nilai-nilai kesakralan.

Oleh karena itu, permasalahan dalam penelitian ini berfokus pada: (1) Bagaimanakah interkoneksi yang terjalin antara tradisi sakral dengan kehidupan Wong Tengger? dan (2) Bagaimanakah mempertahankan tradisi sakral Tengger dari ombang-ambing komodifikasi? Dengan demikian, dapat ditelusuri langkahlangkah strategis yang semestinya diambil dalam rangka "merawat" tradisi Tengger, terutama upacara adat dari ancaman desakralisasi akibat egoisme komodifikasi.

\section{B. METODE PENELITIAN}

$\mathrm{P}$ enelitian ini merupakan penelitian kualitatif untuk menemukan, mengeksplorasi, dan menginterpretasi data penelitian secara holistik dan komprehensif. Adapun desain penelitian yang sesuai adalah penelitian lapangan. Penelitian jenis ini lebih berfokus pada proses pemaknaan dan pendeskripsian. Pendeskripsian yang terkait dengan pemaknaan akan bersifat rich and thick description sehingga pembahasan lebih mendalam.

Tujuan penelitian ini adalah untuk mengidentifikasi langkah-langkah strategis yang semestinya diambil dalam rangka "merawat" tradisi Tengger dari ancaman desakralisasi akibat komodifikasi. Data penelitian yang digunakan berupa ekspresi tradisi ritual spesifik yang utuh, runtut, dan terintegrasi, berwujud ungkapan, tuturan lisan, gerak/tindak serta material bermakna, bergagasan, dan berkaitan dengan ritus sakral tradisi Tengger.

Data penelitian tersebut diperoleh secara langsung dari sumber data berupa pelaksanaan upacara adat Yadnya Kasada, Yadnya Karo, dan Unan-unan Tengger di Desa Tosari dan Desa Ngadiwono, Kecamatan Tosari, Kabupaten 
Pasuruan. Dalam pengumpulan data pada sumber data digunakan teknik observasi terlibat dan wawancara tidak terstruktur (unstructured) serta terbuka (open ended) terhadap pelaku/penutur langsung atau pemilik tradisi, yaitu dukun adat beserta stafnya, sesepuh desa, dan masyarakat Tengger secara umum yang ditentukan sesuai dengan sejumlah kriteria khusus. Proses analisis data dimulai sejak pengumpulan data dilakukan. Data-data yang terkumpul akan direduksi hingga dapat dilakukan penyajian data dan penarikan kesimpulan atau interpretasi data (Rijali, 2018:9495).

\section{HASIL DAN PEMBAHASAN}

\section{Refleksi Kearifan Lokal dalam Upacara Adat Tengger}

T engger adalah masyarakat adat yang dengan taat menjalankan ajaran leluhurnya hingga kini. Hal tersebut diimplementasikan secara konsisten dengan melaksanakan upacara adat, di antaranya upacara Yadnya Kasada, Yadnya Karo, dan Unan-unan.

\section{a. Upacara Yadnya Kasada}

Upacara Yadnya Kasada adalah upacara yang dilaksanakan pada bulan Kasada dalam penanggalan kalender Tengger. Upacara ini dilaksanakan di Pura Luhur Poten yang berada di kawasan Lautan Pasir Gunung Bromo. Pada kesempatan tertentu, upacara Kasada juga dilaksanakan bersamaan dengan pelaksanaan Mulunen. Mulunen adalah ujian menjadi dukun di Tengger yang diselenggarakan sekali dalam satu tahun pada bulan Kasada (Sony Sukmawan et al., 2018, p. 17). Sesaji utama dalam Yadnya Kasada adalah hongkek. Hongkek berasal dari kata Hong yang bermakna Mahakuasa dan Kek bermakna leluhur cikal bakal. Sesaji ini akan dilarung ke kawah Bromo sebagai persembahan kepada Sang Mahakuasa dan para leluhur cikal bakal Tengger sebagai ungkapan rasa syukur dan terima kasih atas limpahan hasil bumi yang telah diberikan kepada Wong Tengger. Hongkek terdiri dari pohon piji (mirip palem), bungkil (batang) pisang, palawiji, dan tujuh buah pras.

Adapun pelaksanaan Kasada diawali dengan pengambilan air suci (tirta) dari Goa Widodaren. Pengambilan air suci ini dilakukan sebelum hari $\mathrm{H}$ pelaksanaan Kasada. Kemudian, pagi hari pada hari $\mathrm{H}$ pelaksanaan, para perangkat adat, pinisepuh suku Tengger, dan perwakilan pemerintahan menghadiri pembukaan upacara Kasada yang dilakukan secara simbolis oleh ketua pelaksana Kasada. Selain itu, tokoh-tokoh penting yang hadir dalam pembukaan ini disuguhi pementasan Sendratari Rara Anteng dan Joko Seger serta pementasan hiburan yang lainnya. Selanjutnya, upacara inti dilangsungkan di Pura Luhur Poten yang dipimpin oleh para Dukun Adat Tengger dengan dilengkapi berbagai persembahan yang akan dilarung di kaldera Gunung Bromo.

Setelah tahapan inti Kasada selesai, selanjutnya Mulunen. Para calon dukun dipersilakan ke Sanggar Agung Poten. Kemudian, duduklah tiga orang dukun di Sanggar Agung Poten yang akan 'menyeleksi' para calon dukun tersebut. Saat perpindahan calon dukun dari Mandala Nista menuju Sanggar Agung Poten, diiringi tabuhan ketipung dan masyarakat semakin antusias. Kemudian, acara mulunen dibuka oleh Ketua Paruman Dukun. Beliau pula yang memandu upacara Mulunen hingga akhir. Selanjutnya, prosesi Mulunen dimulai. Calon dukun satu per satu dipanggil dan dipersilakan membaca mantra tertentu yang sudah ditentukan. Kemudian, lulus tidaknya calon dukun tersebut langsung diputuskan di tempat. Setelah pembacaan mantra selesai, pemandu acara bertanya kepada para dukun dari brang kulon dan wetan untuk mengonfirmasi apakah calon dukun dapat dikatan 'Iulus' atau tidak. Setiap calon dukun diberi tiga kali kesempatan untuk mengulang mantra yang dibacakan jika mengalami hambatan, seperti lupa atau terbatabata. Adapun kelancaran selama 'ujian' sangat ditentukan oleh restu dari dewa dan leluhur Tengger. Biasanya, jika tidak direstui maka hafalan yang akan diucapkan ketika pengujian dukun baru akan mendadak hilang atau menjadi lupa (Sony Sukmawan et al., 2018, p. 17).

\section{b. Upacara Yadnya Karo}

Upacara Yadnya Karo adalah upacara besar selanjutnya yang dilaksanakan oleh masyarakat Tengger. Upacara ini dilaksanakan pada pertengahan bulan Karo berdasarkan kalender Tengger. Karo adalah upacara yang secara khusus dilaksanakan untuk nylameti wong loro, yakni memohon keselamatan bagi laki-laki dan perempuan (Sony Sukmawan, 2020). Hal ini dilandasi oleh legenda Karo yang mengisahkan Setya dan Setuhu sebagai kawula Ajisaka. Dalam rangkaian upacara Karo, terdapat pementasan tarian sakral, yaitu tari Sodoran. Tari Sodoran merefleksikan pengetahuan sangkan paraning dumadi yang disimbolisasikan ke dalam bentuk tarian manusia agar manusia Tengger dapat memahmi dan terus mengingat tentang bagaimana kehidupan ini bermula dan akan ke mana kembalinya (Sukmawan, Nurmansyah, Achmad, et al., 2020b, p. 41). Jika berbagai jenis seni sebelumnya direspons dengan meriah dan penuh kebahagiaan, seni sodoran dibawakan dan disaksikan dengan penuh kekhususkan, bahkan keharuan (Sukmawan, Nurmansyah, \& Febriani, 2020a).

Karo diawali dengan pelaksanaan mepek yang dilakukan satu hari sebelum pembukaan karo/sodoran dilaksanakan. Pembukaan Sodoran dilaksanakan di balai desa pada dini hari. Dinamakan upacara Pembukaan Sodoran karena 
pada hakikatnya, upacara Karo dibuka dengan melaksanakan pementasan Sodoran oleh para sesepuh desa Tengger. Dalam pelaksanaanya, dilaksanakan mblara'i. Mblara'i ditandai dengan penampilan tiga kali tari Sodoran, yakni diawali dengan pementasan yang dilakukan oleh dua pasang penari, dilanjutkan oleh tiga pasang penari, dan terakhir oleh enam pasang penari. Kemudian, melaksanakan rangkaian berikutnya, yakni Santi atau dederek pribadi. Santi adalah upacara yang dilaksanakan di setiap rumah-rumah masyarakat Tengger. Dukun didampingi oleh stafnya akan berkeliling ke setiap rumah warga untuk melaksanakan upacara ini. Untuk satu desa, biasanya memakan waktu hingga satu minggu lebih. Menurut paparan Dukun Pandita Tengger, hakikat santi adalah untuk megundang roh-roh leluhur keluarga. Kemudian, mereka 'diberi' sesaji. Setelah itu, 'disuruh makan'. Selanjutnya, keluarga berbakti kepada para leluhur tersebut atau mendoakan agar arwah para leluhur mereka tenang di alamnya ${ }^{1}$. Rangkaian terakhir dalam upacara Yadnya Karo adalah bawahan. Bawahan adalah upacara penutupan rangkaian Yadnya Karo. Di desa Tosari, bawahan dilakukan di masing-masing dusun, tepatnya di Punden.

\section{c. Upacara Unan-Unan}

Jika upacara Yadya Kasada dan Yadnya Karo dilaksanakana secara rutin satu kali dalam setahun, maka upacara besar dan tidak kalah pentingnya dalam tradisi Tengger, yaitu upacara lima tahunan Unan-unan. Unan-unan biasanya dilaksanakan pada pertengahan bulan kapat kedua dalam perhitungan kalender Tengger (S. Sukmawan, Setiawati, Rizal, et al., 2020). Secara rutin, Unanunan dilaksanakan di Balai Desa dan diikuti oleh seluruh masyarakat. Tujuan pelaksanaan Unanunan terbagi menjadi dua, yaitu (i) untuk mengupacarai waktu yang dikurangi dalam proses perhitungan kalender Tengger (mecak) atau dalam istilah lain disebut nemu gelang, dan (ii) untuk mengupacarai alam semesta beserta seluruh isinya agar senantiasa diberi keselamatan, kesejahteraan, dan kemuliaan hidup.

Sebagai folklor, Unan-unan ada dengan akar tradisi dan nilai-nilai kesakralan yang sangat kuat. Di dalam Unan-unan termuat sejumlah pengetahuan tradisional masyarakat Tengger tentang mbeduduk, tata letak sesaji, dan pitungan. Mbeduduk merepresentasikan perilaku arif Wong Tengger terhadap binatang. Tata letak sesaji merepresentasikan pemahaman mendalam tentang alam makro-mikrokosmos Wong Tengger. Sementara itu, pitungan merepresentasikan pemahaman yang baik dalam diri Wong Tengger terhadap ilmu astronomi tradisional. Kuatnya nilainilai tradisional di dalam Unan-unan sangat

\footnotetext{
${ }^{1}$ Wawancara dengan Pak Puja Pramana, Dukun Pandita Ngadiwono, 2019
}

151 | P a g e

https://doi.org/10.25077/jantro.v23.n2.p148-156.2021 ditentukan oleh seberapa kuat dan jauh transmisi tradisi dilakukan. Unan-unan juga tidak luput dari adanya variasi-variasi pelaksanaan di setiap daerahnya. Walaupun demikian, Unan-unan tetap diyakini dan dilaksanakan dengan sepenuh hati sebagai penunai kewajiban bagi Wong Tengger.

\section{Memakna Nilai Filosofis Tradisi guna Meraih Keselarasan Kosmis}

Pelbagai upacara yang dilaksanakan secara ajeg oleh Wong Tengger adalah upacara yang sarat akan nilai-nilai filosofis. Nilai-nilai filosofis ini juga secara intensif memuat pesan-pesan ekologis yang sangat bertautan dengan sikap hidup Wong Tengger dalam memaknai dan menjalani kehidupan. Yadnya Kasada, Yadnya Karo, dan Unan-unan adalah kristalisasi dari pandangan kosmis Wong Tengger terhadap alam semesta, bagaimana alam semesta bekerja dan seluruh unsur di dalamnya saling terkoneksi satu sama lain. Dalam konteks ini, pembahasan berfokus kepada bagaimana relasi antara tradisi dan alam Tengger sebagai dua unsur yang tidak terpisahkan dan bagaimana keduanya mampu saling memengaruhi. Triyoga (2010, p. 5) mengungkapkan bahwa hubungan antara orang Jawa dengan alamnya bukanlah bersifat eksploitatif agar ia mendapatkan keuntungan sebesar-besarnya, tetapi lebih bersifat saling menjaga agar tercipta keselarasan. Manusia sebagai bagian kecil dari alam semesta harus senantiasa menempatkan diri pada posisi yang tepat, yakni posisi yang sejajar, seimbang, dan selaras dengan alam. Pengingkaran terhadap posisinya akan menyebabkan kehancuran bagi dirinya sendiri dan sebaliknya ia akan selamat jika menempatkan dirinya dalam posisi yang sebenarbenarnya (Triyoga, 2010, pp. 8-9). Hal ini menunjukkan bahwa keharmonisan relasi antara dua unsur ini (alam dan manusia) menjadi sangat penting, sehingga ketika ada laku tradisi yang tidak sesuai akan berdampak pada keseimbangan alam yang akan mengancam keselamatan manusia.

Penelitian Triyoga (2010) terhadap masyarakat lereng Gunung Merapi menemukan nilai-nilai ekologis kaitannya dengan relasi antara manusia dengan alam. Keberadaan Gunung Merapi sebagai bagian dari alam makro, tidak saja dimaknai secara literal, melainkan juga dihayati secara kosmik. Gunung Merapi dipercayai sebagai tempat besemayamnya makhluk-makhluk halus yang dinamakan Keraton Makhluk Halus. Oleh karena itu, sebagian besar penduduk menganggap letusan Merapi justru sebagai anugerah karena setelah itu kehidupan akan menjadi tenang dan baik (Triyoga, 2010, p. 85). Demikian pula, dengan masyarakat lereng Gunung Kelud. Ajaran moral etika yang terkandung di dalam kearifan lokal menuntun masyarakat tradisional Gunung Kelud mampu memandang bencana erupsi sebagai berkah Tuhan (Herminingrum \& Junining, 2016). 
Kami percaya, jika Gunung Bromo erupsi dan menimbulkan hujan abu itu merupakan pupuk alami untuk tanaman. Apabila terdapat tanaman yang mati akibat hujan abu dari Gunung Bromo, itu merupakan pertanda dari para leluhur bahwa mereka sedang membutuhkan makanan. Kematian tanaman tersebut merupakan simbolis bahwa para leluhur telah "mengambil" makanan dari tanaman milik anak cucunya. Kami juga meyakini bahwa tanaman yang ditanam setelah peristiwa hujan abu tersebut akan tumbuh dengan subur.

(Wawancara dengan Pak Puja Pramana, Dukun Pandita Ngadiwono, 2019)

Jika terjadi kesalahan dalam perhitungan kalender Tengger, Gunung Bromo pasti akan memberikan 'firasat'. Oleh karena kesalahan tersebut, pada 2006, terjadi erupsi. Sementara pada 2007, terjadi kemacetan selama berharihari di Bromo karena dipenuhi banyak sekali orang. Barulah setelah 'diingatkan' oleh Gunung Bromo, masyarakat Tengger menyadari bahwa acuan penghitungan kalender Tengger tidak lagi sesuai dengan keadaan alam.

(Wawancara dengan Pak Eko Warnoto, Dukun Pandita Telogosari, 2019)

Secara implisit, keyakinan informan di atas mengejawantahkan relasi antara manusia dan alam Tengger. Hal tersebut tampak pada bagaimana cara pandang Wong Tengger terhadap keberadaan Gunung Bromo. Oleh orang Tengger, Gunung Bromo bukan hanya dianggap gunung suci, tetapi juga gunung yang membawa berkah (Sutarto, 2015). Gunung Bromo dihayati sebagai tempat bersemayamnya leluhur-leluhur Wong Tengger, sehingga apa saja yang "dimuntahkannya" dimaknai sebagai berkah. Namun, pada sisi yang lain Gunung Bromo juga diposisikan sebagai "alarm" bagi kehidupan sosial masyarakat setempat. Selain dianggap sebagai berkah, letusan Gunung Bromo juga acapkali dimaknai sebagai peringatan dari para Leluhur Tengger bahwa sesuatu yang salah telah terjadi di Tanah Hila-hila 'Tanah Suci'. Jika demikian, Wong Tengger akan melakukan sejumlah ritual adat dalam rangka memulihkan ketidakseimbangan menuju keselarasan.

Wong Tengan demikian, baik-tidaknya laku hidup dengan/memengaruhi baik-tidaknya laku alam terhadap dirinya. Oleh karena itu, Wong Tengger mereksa dan menghormati alam dengan sungguhsungguh melalui pelaksanaan ritual keseharian agar tetap berada pada posisi yang tepat, harmonis, dan seimbang. Ini menunjukan bahwa hubungan orang Tengger dengan gunung adalah hubungan dua sahabat yang saling menghidupi dan saling menghormati (Sutarto, 2015, p. 163).

Selain itu, pelibatan unsur alam sebagai sesaji dalam ritual-dengan segenap makna simboliknya-menegaskan bahwa baik secara implisit maupun eksplisit, hidup Wong Tengger sangat bergantung terhadap alam. Ada keselarasan antara pelaksanaan tradisi Tengger dengan keberadaan alam di sekitarnya. Integrasi antara manusia dan alam dalam komunitas ekologis adalah sebuah kenyataan yang menjelaskan adanya keterkaitan, keterikatan, dan ketakterpisahan relasi antara manusia dengan alam (Sukmawan, Rizal, dan Nurmasyah, 2018:53). Manusia Tengger sangat menjaga relasi ini yang diwujudkan melalui pelaksanaan ritual adat. Hal tesebut dilakukan agar manusia Tengger senantiasa berada dalam keselarasan kosmis. Keselarasan kosmis adalah muara dari semua hulu ritus adat, sikap, dan keyakinan yang dipelajari dan diyakini selama berpuluh-puluh tahun oleh masyarakat Tengger agar dalam keselarasan optimal dengan alam raya dan dengan roh-roh yang menghuninya (Sukmawan, Rizal, dan Nurmasyah, 2018:52).

Pada tahun 2006-2007 pernah terjadi pelaksanaan Kasada terlambat selama 3 hari. Pada saat itu, bulan sudah benjol tetapi di kalender masih tertulis tanggal 15, padahal seharusnya sudah memasuki tanggal 1. Antara Brang Wetan dan Brang Kulon juga memiliki perhitungan masing-masing sehingga menjalankan Kasada sendiri-sendiri dalam hari yang berbeda. Keduanya kukuh dengan pendapatnya masing-masing, padahal semuanya tidak ada yang benar. Hal ini dikarenakan 3 kali perputaran rumus, tidak pernah diganti sehingga tidak sinkron dengan keadaan alam.

(Wawancara dengan Pak Eko Warnoto, Dukun Pandita Telogosari, 2020)

Perlu digarisbawahi bahwa keselarasan kosmis dapat tercapai, jika adat tradisi Tengger tetap terjaga. Dengan demikian, kesakralan akan senantiasa terpelihara. Kepatuhan, kepasrahan, dan kerja keras Wong Tengger adalah bagian vital pemertahanan adat. Sikap tersebut senyatanya bukanlah sikap fatalistik, melainkan optimisme yang tidak progresif karena di tengah kepasrahan mereka, ada kerja keras yang tidak kenal menyerah. Dukun Tengger berserta stafnya mengabdikan diri kepada masyarakat tanpa mengenal batas waktu. Mereka ikhlas mengesampingkan ego personalnya demi kepentingan masyarakat (Febriani et al., 2018, p. 884). Pada akhirnya, muara dari segala sikap yang ditampilkan oleh dukun adat beserta stafnya adalah semata-mata untuk tujuan mulia, yakni konservasi alam dan tradisi. Keduanya berjalin kelindan menciptakan relasi harmonis antara alam makromikrokosmos. Dengan demikian, sejatinya upacara adat Tengger adalah titik temu di antara relasi itu. 


\section{Tradisi Adaptif sebagai Strategi Preventif Terhadap Komodifikasi}

Pada dasarnya, dinamika zaman sedikitbanyak telah memberikan pengaruh terhadap tradisi Tengger. Agar tradisi itu tetap eksis, dilakukan sejumlah adaptasi dalam beberapa aspek seperti gubahan sesaji dan perangkat ritual. Sebagai contoh, masuknya jajan pasar ke dalam ragam isi sesaji, seperti roti dan beberapa jenis makanan ringan yang dikemas dengan kemasan plastik yang lebih modern. Jajan pasar semacam ini tentu saja bukanlah bagian dari ragam isi sesaji yang autentik sebagaimana yang diwariskan oleh para leluhur Tengger. Namun demikian, pertimbangan-pertimbangan yang mengharuskan tradisi lebih bersesuaian dengan zaman, tetapi tetap mempertahankan makna adiluhungnya selalu menjadi pilihan yang dilematis. Adaptasi ini dilakukan sebagai upaya pemertahanan tradisi agar tidak tenggelam dalam arus kemajuan zaman. Marzali (2003) mengemukakan bahwa strategi adaptasi merupakan tindakan yang tepat guna sesuai dengan lingkungan sosial, kultural, ekonomi, dan ekologis di tempat di mana mereka hidup yang dilakukan manusia dalam mengalokasikan sumberdaya yang mereka miliki dalam menghadapi berbagai masalah. Jajan pasar adalah salah satu contoh adanya transisi dari tradisi lama ke tradisi yang lebih kekinian. Lantas, bagaimana dengan unsur-unsur lain yang telah dan berpotensi akan mengalami transisi yang sama?.

Kemajuan zaman tidak hanya berpengaruh terhadap konstruk sesaji, melainkan juga memengaruhi paradigma masyarakat terhadap upacara sakral di Tengger. Dalam konteks ini, strategi adaptasi dilakukan sebagai respons terhadap perubahan-perubahan yang disebabkan oleh kemajuan zaman. Adaptasi menjadi pilihan logis dalam menyiasati permasalahan ini agar tradisi senantiasa eksis tanpa meniadakan esensi kesakralannya. Ini menunjukkan bahwa kesakralan sangat bergantung pada faktor eksternal yang melingkupi suatu objek. Kesakralan yang dimiliki oleh sesuatu tidaklah muncul dari instrinsik sesuatu tersebut: Kesakralan tersebut diimbuhkan padanya (Durkheim, 2011, p. 337). Jika upacara adat Tengger diposisikan sebagai suatu ritus yang sakral, selamanya, upacara tersebut akan tetap berada pada dimensi yang sakral. Sebaliknya, jika suatu kolektif memosisikan upacara adat sebagai ritus yang tidak lagi sakral, dapat dipastikan kesakralan itu akan hilang sama sekali dalam dirinya.

Yadnya Kasada, Yadnya Karo, dan Unan-unan adalah tiga dari sekian banyak upacara yang disakralkan oleh masyarakat Tengger. Yadnya Kasada adalah upacara penghaturan syukur dan terima kasih Sang Hyang Widhi dan para leluhur Tengger atas limpahan hasil bumi yang telah mereka terima. Melalui labuh sesaji berupa hasil bumi ke dalam kaldera Gunung Bromo, masyarakat
Tengger memanjatkan doa dan harapan agar senantiasa dilimpahi hasil bumi yang baik dan berkepanjangan. Sementara dalam pelaksanaan Yadnya Karo, tangis haru menyeruak di antara gerak sederhana tetapi penuh makna tari Sodoran yang melukiskan perjalanan kehidupan manusia; dari mana kehidupan berasal, bagaimana kehidupan itu dijalankan, dan akan ke mana kembalinya. Nuansa sakral penuh haru ini selaras dengan pemahaman masyarakat Tengger dalam memaknai sangkan paraning dumadi yang termuat dalam tari Sodoran. Demikian pula dalam Unanunan, relasi harmonis antara alam dan manusia dihayati sebagai sebuah hubungan yang sakral. Perhitungan waktu yang ditetapkan melalui proses mecak diselamati setiap lima tahun sekali. Upacara ini ditujukan agar dalam setiap waktu, alam semesta beserta seluruh isinya selalu berada dalam keadaan yang sempurna, genap, dan seimbang.

Di antara upacara-upacara yang rutin dilaksanakan oleh Wong Tengger, Yadnya Kasada adalah upacara yang sangat sukses dalam meningkatkan nilai jual pariwisata kawasan Gunung Bromo. Pada awalnya, Yadnya Kasada dan Karo merupakan upacara tradisional yang hanya dilaksanakan oleh masyarakat lokal. Namun, sejak tahun 2000-an, upacara-ipacara tersebut, terutama Kasada, mulai digandrungi oleh para turis karena keunikan dan kemenarikannya sebagai sebuah tontonan (Rosyidi, 2018). Upacara Yadnya Kasada 'dijajakan' sebagai komoditas utama-tahunandalam brosur-brosur, spanduk-spanduk, dan unggahan-unggahan media sosial yang menawarkan perjalanan wisata dalam dan budaya yang menarik. Hal tersebut sebagaimana yang tampak pada beberapa brosur berikut.

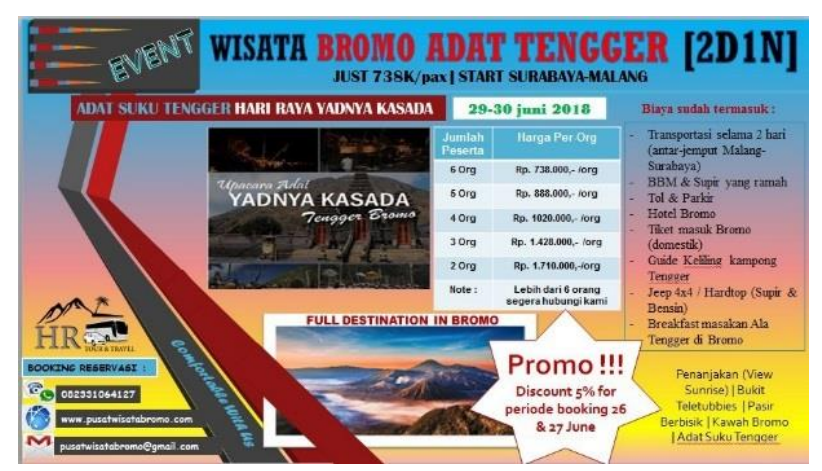

Gambar 1. Brosur paket wisata Bromo Sumber: https://www.pusatwisatabromo.com 


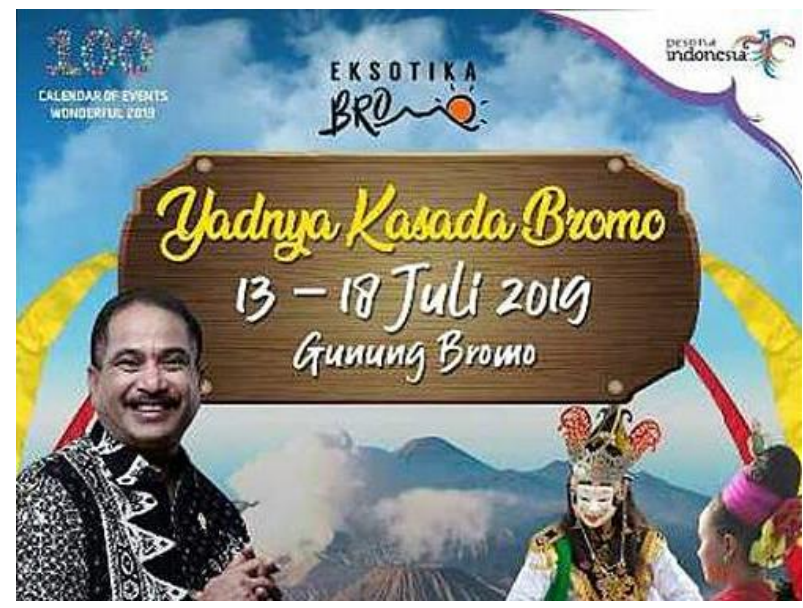

Gambar 2. Brosur Festival Eksotika Bromo Sumber: https://today.line.me

Dalam konteks tertentu, kemajuan pariwisata yang ditandai dengan lonjakan wisatawan yang berkunjung tentu saja menjadi kabar menggembirakan, mengingat tidak sedikit Wong Tengger yang bertaruh hidup dalam sektor ini. Selain Kasada, upacara Karo dan Unan-unan juga menarik perhatian wisatawan, meskipun tentu saja animonya tidak setinggi Kasada karena kedua ritual ini dilaksanakan di kawasan pemukiman Wong Tengger, bukan Gunung Bromo. Selain itu, sebagaimana di Bali, Tengger juga memiliki tarian khas dan sakral, yakni tari Sodoran. Kekhasan inilah yang menjadi magnet bagi para wisatawan untuk datang dan menyaksikan pertunjukan yang tidak bisa mereka temui di tempat lain.

Di samping itu, Yadnya Kasada, Yadnya Karo, dan Unan-unan senyatanya telah membuka ruang eksistensi bagi destinasi wisata alam lainnya yang terdapat di kawasan Bromo. Himah, dkk., (2020:113) mengungkapkan bahwa ... secara tidak langsung, melalui Kasada, masyarakat Tengger bisa memperlihatkan budaya yang dimilikinya dan pelajaran dibalik keberanekaragaman adat istiadat tersebut, sehingga banyak dari wisatawan yang tertarik untuk mengetahui budaya mereka. Kendati demikian, pada ranah yang lebih internal, tentu saja sikap profan ini menimbulkan kekhawatiran. Pariwista Tengger dan pariwisata di Indonesia pada umumnya selalu berkiblat ke Bali sebagai tolok ukur kesuksesan pariwisata berbasis alam dan kebudayaan. Hal ini selaras dengan pernyataan Alfath \& Permana bahwa untuk pariwisata alam dan budaya, seluruh daerah di Indonesia selalu bercermin kepada kesuksesan Bali (2016, p. 170).

Di Bali telah banyak terjadi komodifikasi budaya demi kemajuan industri pariwisata. Komodifikasi adalah proses terjadinya perubahan barang atau layanan yang sebelumnya mengikuti aturan sosial non-pasar menjadi suatu subjek yang mengikuti aturan pasar (Gleick et al., 2002). Dalam ranah budaya, komodifikasi dapat diterjemahkan sebagai bentuk tindakan yang mengubah unsur- unsur budaya menjadi bernilai secara ekonomi dan dapat diperjualbelikan sehingga menimbulkan modifikasi pada unsur budaya tersebut (Niko \& Atem, 2019). Kendati komodifikasi tersebut ditempuh melalui jalur psedo traditional art, yakni sebuah konsep dalam pengembangan kesenian tradisional dengan cara membuat tiruan bentuk aslinya (Maquet, 1979). Dengan harapan, hakikat dari sebuah tradisi tersebut tidak akan hilang. Jika hal ini diterapkan pula di Tengger, maka persoalannya adalah di manakah nilai-nilai adiluhung yang sakral itu berada? Sebagai contoh, apabila terdapat sebagaian masyarakat Tenggertertentu-yang memiliki angan-angan untuk dapat mengkreasi ulang tari Sodoran dengan waktu dan tempat yang tidak terikat aturan. Tujuannya semata-mata agar tari Sodoran dapat dipentaskan di hadapan wisatawan, tidak hanya ketika dilaksanakan upacara Karo saja. Maka, sesungguhnya secara tidak langsung telah hilang pula kesakralan yang melekat padanya. Sebagai tarian sakral, tari Sodoran tidak diperbolehkan ditarikan di luar upacara Karo dan tidak bisa diajarkan kepada sembarang orang guna menjaga nilai kesakralannya (Sony Sukmawan, Nurmansyah, \& Febriani, 2020). Problematika kesakralan ini tidak hanya menyangkut aspek ini saja, tetapi juga aspek yang lain sebagaimana paparan informan berikut ini.

Tidak ada masalah dengan hadirnya pariwisata di Tengger selagi aktivitas ini tidak menimbulkan masalah. Maksudnya, di sini ada ketentuan khusus, manakah hal yang bisa dikunjungi dan bisa dilihat dan mana yang tidak. Contoh, di Kaldera Bromo ada beberapa tempat yang tidak boleh dikunjungi orang yang sedang dalam keadaan cuntaka (sedang dalam keadaan tidak suci), seperti kawah Bromo dan Widodaren. Inilah kekurangannya. Maksudnya, antara pihak pariwisata dengan sesepuh di sini belum pernah dilakukan koordnasi tentang hal itu. Kalau sudah dikoordinasi sebenarnya bisa diberikan papan atau intruksi-instruksi yang sesuai dengan aturan adat.

(Wawancara dengan Pak Eko Warnoto, Dukun Pandita Telogosari, 2020)

Paparan informan di atas menunjukkan bahwa dalam proses beradaptasi dengan modernisasi dan mengakomodasi industri pariwisata, keputusan dan tindakan yang arif adalah langkah yang dapat dilakukan untuk menyelaraskan kepentingan kepariwisataan dengan marwah kultural masyarakat lokal. Artinya, kebijakan pariwisata tidak hanya bertumpu pada orientasi ekonomis, tetapi juga bertumpu pada nilai-nilai adiluhung suatu tradisi. Hal tersebut semata-mata dilakukan untuk menjaga keautentikan dan kesakralan tradisi. Salah satu cara yang dapat ditempuh adalah dengan melibatkan penuh para pemangku adat Tengger sebagai pemilik kebudayaan-yang selama ini tampak terabaikan-dalam menetapkan 
kebijakan-kebijakan strategis ini. Perlu dirembukkan secara mendalam dan sungguh-sungguh untuk membuat klasifikasi-memisahkan-mana tradisi yang sakral serta tidak bisa dikomodifikasi dan mana tradisi yang di luar lingkaran kesakralan dan bisa dikomodifikasi. Lebih jauh lagi, kebijakankebijakan strategis lainnya yang mengacu pada kearifan tradisi Tengger dapat didiskusikan secara intensif. Dengan demikian, segala bentuk kesakralan yang menapasi kehidupan Wong Tengger tetap berada pada makna esensialnya tanpa menafikan arus moderninasi yang semakin hari semakin deras lajunya.

\section{KESIMPULAN}

$\mathrm{R}$ entak zaman bukanlah satu hal yang harus ditakuti, melainkan pola pikir masyarakat yang harus senantiasa direksa agar tetap sedia menjalankan titiluri. Untuk melaksanakannya, pertama-tama keyakinan dan kepatuhan dalam menjalankan ajaran leluhur harus diimbangi dengan pemahaman secara mendalam dan komprehensif tentang kebudayaan yang dimiliki. Setelah proses internalisasi dilakukan, setiap elemen yang menjadi bagian dari kebudayaan tersebut harus gugur gunung, yakni turut mereksa eksistensi tradisi tanpa menghilangkan esensi kesakralan yang telah melekat padanya.

Salah satu cara yang dapat dilakukan adalah dengan tetap memisahkan kesakralan tradisi dari kungkungan profanisasi. Langkah ini dapat ditempuh jika terjalin koordinasi yang optimal antara pengelola sektor pariwisata dan para pemangku adat. Melalui koordinasi ini, industri pariwisata dan praktik adat tidak berjalan secara sendiri-sendiri, melainkan berjalan beriringan untuk menciptakan nuansa kepariwisataan yang lebih bermuatan kultural. Misalnya saja, tradisi-tradisi apa atau tempat-tempat mana saja yang boleh dan tidak boleh "diusik" oleh wisatawan harus secara tegas diimplementasikan oleh pemangku sektor kepariwisataan. Hal ini bertujuan untuk menghindari ketumpangtindihan antara regulasi kepariwisataan dan kepercayaan adat yang telah melekat pada masyarakat Tengger.

Sejatinya, komodifikasi menjadi sangat mungkin terjadi untuk mengakomodasi kemajuan industri pariwisata. Benar bahwa melalui komodifikasi, tradisi dapat dilestarikan. Akan tetapi, melalui komodifikasi pula, kesakralan suatu tradisi dirampas dari hakikatnya. Oleh karena itu, sikap bijak, sinergis, dan koordinatif antar-berbagai pihak menjadi kunci dalam kesuksesan industri pariwisata TNBTS. Industri yang dibangun dengan menunjung keluhuran nilai-nilai kearifan lokal suku Tengger.

\section{E. UCAPAN TERIMA KASIH}

$\mathrm{S}$ edalam-dalamnya terima kasih penulis sampaikan kepada Wong Tengger, terutama keluarga besar Romo Dukun Pandita Puja Pramana, Romo Dukun Pandita Eko Warnoto, dan Bapak Kariadi yang selalu membukakan pintu rumah dan pintu pengetahuan bagi saya dalam memahami budaya Tengger. Selain itu, terima kasih saya sampaikan pula kepada Dr. Sony Sukmawan, M.Pd. guru yang senantiasa membimbing saya dalam memahami Tengger. Terima kasih saya sampaikan pula kepada dosen pengampu mata kuliah "Teori Kajian Budaya Kontemporer", yakni Prof. Diah Ariani Arimbi, S.S., M.A., Ph.D. dan asisten beliau, yakni Mbak Nadia Egalita. Tulisan ini tentu saja tidak akan mampu disusun dengan baik tanpa bimbingan, kritik, dan saran dari beliau.

\section{DAFTAR PUSTAKA}

Alfath, E. D., \& Permana, Y. S. (2016). Festival 1000 Tumpeng: Komodifikasi tradisi, pariwisata, dan 'territoriality' di Gunung Kelud. Masyarakat, Kebudayaan Dan Politik, 29(4), 169-180. https://ejournal.unair.ac.id/MKP/article/view/2613

Dewi, P. (2016). Komoditas Tari Barong di Pulau Bali. Panggung, 26(3).

Durkheim, E. (2011). The Elementary Forms of The Religious Life: Sejarah Bentuk-bentuk Agama yang Paling Dasar. IRCiSoD.

Febriani, R., Prihandini, C. W., \& Manda, M. S. (2018). Slametan Tengger sebagai Mekanisme dalam Menjaga Tradisi dan Membangun Integrasi. Prosiding Industrial Research Workshop and National Seminar, 9, 784-789.

Gleick, P. H., Wolff, G., Chalecki, E. L., \& Reyes, R. (2002). The New Economy of Water: The Risk and Benefits of Globalization and Privatization of Fresh Water. acific Institute for Studies in Development, Environment, and Security.

Hasanah, D. F., \& Sukmawan, S. (2020). Titiluri Tegger: Aktualisasi Tradisi, Refleksi Jati Diri dan Strategi Konservasi. LINGUA: Jurnal Bahasa, Sastra, Dan Pengajarannya, 17(2). https://doi.org/10.30957/lingua.v17i2.643 
Herminingrum, S., \& Junining, E. (2016). Socio-Cultural Life Of Kelud People In Connecting With Traditional Mitigation Effort Based On Local Wisdom. International Journal of Social and Local Economic Governance, 2(2), 127-135. https://ijleg.ub.ac.id/index.php/ijleg/article/view/54

Hikmah, K., Sazjiyah, S. R., \& Sulistyowati, T. (2020). Dinamika Kehidupan Masyarakat Suku Tengger Dibalik Kegiatan Pariwisata Bromo. Journal of Tourism and Creativity, 4(2), 105-116. https://jurnal.unej.ac.id/index.php/tourismjournal/article/view/14818/8660

Maquet, J. (1979). Introduction to aesthetic anthropology. Undena Publications.

Marzali. (2003). Strategi Peisan Cikalong dalam Menghadapi Kemiskinan. Yayasan Obor Indonesia.

Mba, D. A. (2020). Ekowisata sebagai Bentuk Adaptasi Masyarakat Liang Ndara pada Pariwisata. Urnal Antropologi: Isu-Isu Sosial Budaya, 22(2), 198-207. https://doi.org/https://doi.org/10.25077/ jantro.v22.n2.p198-207.2020

Niko, N., \& Atem, A. (2019). Festival Air (Songkran): Komodifikasi Budaya di Thailand. Simulacra, 2(1), 2130. https://journal.trunojoyo.ac.id/simulacra/article/view/5518

Pramono, S. (2020). Siapa Sebenarnya Pengelola Kawasan Wisata Bromo? Kumparan. https://kumparan.com/sigitpramono/siapa-sebenarnya-pengelola-kawasan-wisata-bromo1 ssl1eE6SiF

Rijali, A. (2018). Analisis Data Kualitatif Ahmad Rijali UIN Antasari Banjarmasin. Jurnal Alhadharah, 17(33), $81-95$.

Rosyidi, M. I. (2018). The Challenges of Developing Tourism Events in Bromo Tengger Semeru National Park. Journal of Indonesian Tourism and Development Studies, 6(3), 159-166. https://www.jitode.ub.ac.id/index.php/jitode/article/view/266

Sasongko, Y. (2019). Desakralisasi Kecak Bali. https://beritabaru.co/desakralisasi-kecak-bali/

Sukmawan, S., Setiawati, E., Rizal, M. S., \& Febriani, R. (2020). Dimensi Ekologi Folklor Unan-Unan Tengger. Jurnal IImiah Edukasi \& Sosial, 11(1), 60-66. http://jiesjournal.com/index.php/jies/article/view/224

Sukmawan, Sony. (2020). The Gastronomy of Tenggerese's" Cangkriman-Sodoran" Oral Literature. Lensa: Kajian Kebahasaan, Kesusastraan, Dan Budaya, 10(2), 167-178. https://jurnal.unimus.ac.id/index.php/lensa/article/view/5924

Sukmawan, Sony, Nurmansyah, M. A., Achmad, A. M., \& Febriani, R. (2020). Sodoran Karo: Telaga Edukasi, Seni, Tradisi, dan Gastronomi Tengger. Media Nusa Creative.

Sukmawan, Sony, Nurmansyah, M. A., \& Febriani, R. (2020). Sodoran as a Means of Intromission Education for Tenggerese Younger Generation. International Seminar on Social Science, Humanities, and Education.

Sukmawan, Sony, Rizal, M. S., \& Nurmansyah, M. A. (2018). Green Folklore. Universitas Brawijaya Press.

Sutarto, A. (2006). Sekilas tentang masyarakat Tengger. Makalah Disampaikan Pada Acara Pembekalan Jelajah Budaya, 7-10.

Sutarto, A. (2015). Orang Tengger dan Gunung dalam Kumpulan Artikel "Gunung, Bencana, dan Mitos di Nusantara." Penerbit Ombak.

Syafrita, I., \& Murdiono, M. (2020). Upacara Adat Gawai Dalam Membentuk Nilai-Nilai Solidaritas Pada Masyarakat Suku Dayak Kalimantan Barat. Jurnal Antropologi: Isu-Isu Sosial Budaya, 22(2), 151-159. https://doi.org/https://doi.org/10.25077/jantro.v22.n2.p151-159.2020

Triyoga, L. S. (2010). Merapi dan Orang Jawa: Persepsi dan Kepercayaannya. Gramedia Widiasarana Indonesia.

Utami, H. S. (2017). Pengelolaan Kawasan Pariwisata (Studi di Balai Besar Taman Nasional Bromo Tengger Semeru). Jurnal IImiah Administrasi Publik, 3(1). https://jiap.ub.ac.id/index.php/ jiap/article/view/653 